\title{
Supervisors' Reactions to a Counseling Interview
}

\author{
GARRY R. WALZ \\ and \\ EDWARD C. ROEBER \\ University of Michigan
}

Recent developments in counselor education have seen widespread support for the assignment of supervised counseling practice to a central position in counselor education. Both the APGA policy statement (4) and the APA Division 17 statement (1) on counselor education accord a major position to supervised practice. It is noteworthy that the APGA statement calls for supervised practice “. . . to consume approximately onefourth of the entire counselor education program ...", while an earlier APA statement on counselor training states that, "The practicum is in some respects the most important phase of the whole process of training in counseling." (2, p. 183) Further support for supervised experience is provided by the Wrenn Report, the increased emphasis given to the supervised experience in recent NDEA Counseling and Guidance Institutes and the emphasis given it by recent writers.

Of particular interest is that the discussions and writings have not generally devoted attention to an important aspect of supervised counseling practice, namely, the supervisory process. The large majority of writings devoted to counselor supervision concern themselves with techniques and procedures useful in supervision rather than with the relationship between the supervisor and the counselor candidate, and the process by which the supervisor assists in the professional and personal development of the candidate. Sanderson (3) is rare among textbooks authors in devoting a chapter to the supervision of counselors; the usual practice is to make only passing references to supervision. The APGA statement skirts the topic by referring to conditions for the counseling practicum but ignoring the basic nature of the supervision other than to call it “. . a tutorial form of instruction." (4, p. 8) This study was undertaken with the intention of revealing current orientations and procedures in the supervision of counselor trainees. By first defining existing super- 
vision it was believed we would then be able to extend our research to relate supervisory practices to counselor behavior and, hopefully, to develop a model of supervision.

\section{Experimental Procedures}

Considerable thought was given to an appropriate means of sampling supervisory procedures. We especially wished to avoid a questionnaire study which would provide information on who did what, but probably provide little information on the attitudes and feelings which we regard as basic in the supervisory process. Any method selected necessarily had to be specific and concrete enough that it could be explained through written instructions and provide the same stimulus for supervisors in differing situations.

Our decision was to use a typescript of a counseling interview. Each participant was provided with the typescript and background data regarding the counselor and client. The interview was by a beginning practicum student and was notable for several shifts in counselor orientation and technique. It was our belief that the interview was likely to be provocative enough to evoke considerable supervisory response. We were proved to be right in this assumption!

Each participant was asked to respond to the typescript as if it had been given to him by a member of his practicum for his evaluation. The participant was instructed to make all of his comments in writing, either at the point in the interview where his reactions occurred or at the end.

It was apparent that supervisory responses on a typescript would not be a valid sample of the counseling supervision exercised by different supervisors. Some "dry-runs" of the technique did, however, reveal that this approach was remarkably sensitive to revealing the basic orientation and attitudes of the supervisor involved. Since our major concern was to identify such orientations and attitudes, it was felt to be an appropriate instrument for the purposes of this study.

All counselor education programs in the North Central Region which listed a counseling practicum in their program were contacted as to their interest in participating in a study on counseling supervision. Of the twenty-nine contacted, twenty-six affirmative replies were received. The analysis was made on 22 completed typescripts; four dropped out of the study because of "professional moves" or "heavy work loads." The idea was well received by those contacted, and the completed typescripts evidenced the expenditure of considerable time and thought.

The analysis of the typescripts involved two basic steps. The first step was to classify each counselor and client response on the interview typescript, sent to each participant, using Rundquist's revision of Snyder's 
Counselor and Client Response Categories. Two judges working together made the classifications. This classification enabled the experimenters to classify each counselor or client response that a supervisor choose to respond to. There were a total of 45 counselor and 44 client statements in the interview.

The second step involved the construction of a seven category Supervisor Response Categories (SRC) classification system. Three judges working together classified the supervisory comments using the SRC. Multiple coding was adopted so that a given supervisory comment could appear in more than one classification. A total of 741 supervisory statements were classified using the SRC, 544 statements directed at the counselors behavior and 197 statements directed at the clients behavior.

\section{Results}

It is important to note that it was not our intention to evaluate or judge supervisory practices. Rather, we wished to identify current orientations and practices which could serve as a guide to further self-study by counseling supervisors. Time and space do not permit a listing of all the data obtained. Somewhat arbitrarily, therefore, the data which seemed most relevant to this discussion were selected for inclusion.

In responding to the interview, supervisors ranged in time from 30 minutes to 132 minutes with a median of 90 minutes. It is noteworthy that a fourth of the supervisors devoted 2 hours or more while another fourth devoted one hour or less. Though there are doubtless many variables present in this time differential it may well be indicative of a real difference regarding the time needed to adequately respond to a typescript.

The focus of supervisory attention would seem to be on the counselor rather than the client. The median number of supervisory comments concerned with the counselor was 25 per interview while those concerned with the client averaged only 9 . Clearly, the supervisors were more concerned with responding to what the counselor said than to what the client said. It should also be mentioned that the content of the supervisory statements rarely contained references to the relationship or the interaction between counselor and client.

Of particular interest in this interview was whether or not the supervisors responded equally throughout the interview or concentrated their responses in any one area. The data revealed there was a pronounced tendency to make fewer responses with each subsequent third of the interview. Though it may be hypothesized that this would be expected it should be noted that there was a major change in the interview dynamics in the last third of the interview, a change which does not seem to have been reflected in the frequency of supervisory response. 
TABLE I

FREQUENCY OF SUPERVISORY COMMENTS CLASSIFIED IN

EACH OF THE SUPERVISOR RESPONSE CATEGORIES (SRC)

Questioning

N 144

Identifying Error

27

Instruction

254

Suggesting Alternatives

22

$\%$ of Total

Interpretation

32

Support

62

Unclassifiable

3

26

Total

544

5

47

4

6

11

1

100

As previously stated, the supervisors focused primarily on counselor rather than client behavior. In focusing on the counselor, what was the nature of their comments? From Table I, it will be seen that 73 percent of the comments were either Questioning or Instruction. Present in most of the forementioned comments was the implication of counselor error. Supportive comments accounted for only 11 percent of the responses. The categories with the least responses were Suggesting Alternatives and Unclassifiable. Generally, it appeared that most of the comments had a strong informational slant to them.

The supervisory responses to the client were similar to the responses to the counselor in that Questioning and Instructional responses predominated, with 24 and 44 percent respectively. A difference was that Interpretation accounted for 24 percent of the responses to client statements while only 6 percent to counselor statements.

Of interest regarding the individual supervisor was the degree of consistency shown. An analysis of the responses suggests that supervisors in general were characterized by a relatively narrow response range; supervisors were identifiable as having one or two characteristic modes of response which they used throughout the interview. Thus over 50\% of the responses in the Suggesting Alternatives category were contributed by one supervisor. Other supervisors also showed large predominances in one or two categories.

Perhaps a question of some importance is whether supervisors respond to the same parts of an interview. The answer to this question can be summarized by both a $Y e s$ and a No answer. The important variable in both frequency and agreement of response would seem to be "desirability." If the consensus of the supervisors is that a counselor statement is "undesirable," it is likely to evoke a large number of similarly classified supervisory responses. If a statement is regarded by some supervisors as a "desirable" response, it is likely to evoke less supervisory responses than the "undesirable" statement and to result in responses covering a variety 
of categories. Apparently, there is greater agreement on "incorrect" than "correct" counselor behavior and a greater inclination to indicate errors than to reinforce desirable behavior.

\section{Conclusions and Implications}

Let us summarize what we have found regarding supervisory behavior. It would seem to be focused on the counselor rather than the client and to be more concerned with the initial than closing stages of the interview. Supervisors responded to counselor candidate behavior primarily by instructional statements and to a lesser degree by raising questions, both frequently implying error. Supervisors showed consistency in response throughout the interview, generally using only one or two response categories. There was greater agreement and frequency of response among supervisors on counselor behavior evaluated as "undesirable" than behavior evaluated "desirable."

Like much research we have probably succeeded in raising many more questions than we have answered. At this stage of our investigation it may be that question raising is more palpable than question answering. Be that as it may, it would seem that we have emerged from this study with several questions that would have particular relevance for the supervisory process. They are herewith raised with the intention that they may serve as guides in the further study of the supervisory process.

1. As identified by this study, the usual supervisory response would seem to be cognitive and information giving, with negative overtones. Essentially, they are rational and evaluative responses. This would suggest that we (supervisors) either feel that the relationship between supervisor and counselor is different than that between counselor or client or that we feel the rationale underlying counseling is inappropriate in this context. Is the relationship between supervisor and counselor more like that of the subject matter teacher and pupil, or like counselor and client? Operationally, we would seem to have defined it as more like the former than the latter.

2. It would seem that in our responses as supervisors we have been more concerned with what the counselor said, than with what he did; more concerned with the content of a counselor statement than his relationship to a client. Is it possible we are reinforcing technique counseling by technique supervision? Would we assist the counselor more in acquiring greater self-understanding of his counseling behavior by focusing on the clients' needs rather than dealing with the specifics of counselor behavior?

3. It has been demonstrated that diagnosis often goes awry because of a diagnosis made too soon, on too little data. In our supervision are we too quick to classify and too insensitive to changes in the relationship? 
Is the most appropriate perspective for an interview that which includes all of the nuances of the relationship and interaction, rather than the impact of single counselor responses? It is perhaps germane to wonder if the supervisory position is leading us to make judgments and evaluations about a counselor rather than to assist the counselor to see the meaning of his behavior.

4. This study has identified a wide range of supervisory behavior. No two supervisors reacted to the same pattern of counselor/client statements or used similar wording and meaning in their statements. Nor did any one supervisor use even a fraction of the total variations in response used by the supervisors as a group. Realistically, differences should be expected. But how large should these differences be? Earlier we mentioned that counselor errors seemed to evoke the greatest supervisory agreement. Is this an indication that our major approach to supervision is a carry-over from when we were classroom teachers and checked papers to see how many errors had been committed?

Left unanswered by this study are the criteria used by supervisors in choosing to respond in the way they did. Further progress in supervision would seem to rest upon more sophisticated studies which would establish criteria usable by supervisors in their daily supervision.

In conclusion, it would seem important to consider standards, as we are doing, but it would also seem necessary to consider the supervisory process itself. The potentialities inherent in a counseling practicum are boundless. A practicum can become, however, a small class in techniques of counseling. There is decided merit in APGA's efforts to provide a realistic load for practicum supervisors. But it would surely seem a lost opportunity to do no more than spend additional time at what we are already doing.

The challenge is not just to acquire more time for supervision, but to make counseling supervision a vital process. Standards, Yes! Further study of the supervisory process, especially Yes!!

Earlier we set as our goal to describe, not to evaluate. Perhaps one evaluation is in order. We seem not to have an underlying rationale for how we supervise! If some of our products counsel from the seat of their pants, perhaps it is because we supervise from the top of our heads.

\section{BIBLIOGRAPHY}

1. American Psychological Association Committee on Counselor Training, Division of Counseling and Guidance. The Practicum Training of Counseling Psychologists. American Psychologist, 1952, 7:182-187.

2. Rundquist, Richard M. A Comparison of the Analysis of Counseling Interviews by Topical Discussion Units and by the Total Case. Unpublished Ed. D. dissertation, University of Missouri, 1952.

3. Sanderson, Herbert. Basic Concepts in Vocational Guidance. New York: McGrawHill, 1954.

4. Standards for the Preparation of School Counselors. A Policy Statement of the American Personnel and Guidance Association. Washington, D. C.,: APGA, 1961. 